\title{
How Serious is the Impact of Type II Diabetes in Rural Kenya?
}

\author{
Hemed El-busaidy ${ }^{*}$, Mariam Dawood, Ahmed Kasay, Changambi Mwamlole, Nahida Koraya and \\ Hafsa Parpia
}

\author{
University of Nairobi, College of Health Sciences, Department of Medicine, Nairobi, Kenya
}

\begin{abstract}
Over 50\% of all adult hospital admissions and 55\% of hospital deaths in Kenya are non-communicable, of which diabetes is among the leading. We aimed to describe the impact of type II diabetes at a rural community in Kenya. 200 healthy adult patients underwent random blood sucrose (RBS) testing after ethical approval by the Isiolo County Hospital. Diabetes was defined as RBS $\geq 11.1 \mathrm{mmol} / 1$. A thorough history, physical examination and dipstick urinalysis for urine protein was done to identify risk factors and/or evidence of end organ damage. 32 patients $(16 \%)$ had RBS $\geq 11.1$ mmol/1. 12 patients (37.5\%) never knew they were diabetic and those who knew $63 \%$ were not taking any medication. The most common risk factors were high fat diet (59.4\%), sedentary lifestyle (46.8\%) and family history of diabetes in first degree relative (37.5\%). 43.7\% of patients $(n=14)$ had abdominal obesity while $21.9 \%(n=7)$ had various foot abnormalities. 8 patients $(25 \%)$ had proteinuria of $\geq+1$ on dipstick urinalysis. The $16 \%$ diabetes prevalence is among the highest recorded for a community living on $\leq 1$ dollar/day. Further, evidence of end organ damage as depicted by massive proteinuria warrants urgent attention to this underprivileged group. It is hoped the results will form basis for future screening of diabetic nephropathy and other diabetes-related end organs involvement in this part of the world.
\end{abstract}

Keywords: Type II diabetes mellitus, rural kenya, risk factors, impact.

\section{INTRODUCTION}

In Kenya, non-communicable diseases (NCD's), of which diabetes is among the leading, are important source of morbidity and mortality [1]. According to WHO, out of the 57 million deaths that occurred worldwide in 2008, 36 million $(63 \%)$ were as a result of Non Communicable Diseases [2]. Approximately 29 million of such deaths occurred in low and middle income countries including Kenya [3]. In African nations in particular, by the year 2030, deaths due to NCDs are expected to increase to 52 million per year, exceeding the combined deaths of communicable and nutritional diseases [4]. It is therefore clear that despite the popular belief that NCDs afflict mostly high-income populations, evidence demonstrates the contrary. Further, according to the Ministry of Public Health of Kenya, over $50 \%$ of all hospital admissions and $55 \%$ of hospital deaths in Kenya are non-communicable, diabetes among the leading.

The incidence of diabetes is increasing in Kenya [5], however, its awareness is still demanding in many rural parts of this country. Further, majority of the rural population in Kenya are highly ignorant of the common etiologies/risk factors for diabetes [6]. Although several studies have described the prevalence and risk factors for diabetes in different parts of Kenya $[5,7,8]$ ) none has quantified the magnitude of this disease in rural Kenya. This study therefore aimed to describe the impact of type II diabetes in a rural community in Kenya.rural Kenya. This study therefore aimed to describe the impact of type II diabetes in a rural community in Kenya.

Address correspondence to this author at University of Nairobi, College of Health Sciences, Department of Medicine, P.O BOX 00100-30197, Nairobi, Kenya; Tel: +254732666777; E-mail: elhemed@gmail.com

\section{MATERIALS AND METHODS}

\section{Study Design and Data collection}

This study was done over a two day period during a free medical screening in the county of Isiolo Kenya, approximately 275 kilometers from the Capital Nairobi. Ethical clearance for the study was obtained from the Isiolo County Hospital. All adults ( $\geq 18$ years) were eligible to participate in the study. Those who gave informed consent and agreed to provide blood and urine samples were enrolled. A total of 200 adults were available for the study. The socio-demographic and clinical correlates related to diabetes mellitus were obtained. These included age, sex, occupation, level of education, body mass index (BMI), smoking, alcohol, family history of diabetes/hypertension, diet and physical activity. A thorough history and focused physical examination was done to identify potential risk factors and/or evidence of end organ damage. Diabetes was defined as random blood sugar $>11.1 \mathrm{mmol} / \mathrm{l}$ while hypertension was diagnosed if systolic blood pressure was $\geq 140 \mathrm{mmHg}$ and/or diastolic blood pressure $\geq 90 \mathrm{mmHg}$. Sedentary lifestyle was defined as walking $<25$ minutes/day. Random blood glucose measurement was performed using Ascensia Glucometer, Bayer Healthcare (Germany) while a standard urine dipstick was used to test for overt proteinuria (Multistix 10SG, Siemens, USA).

\section{Data Analysis}

Data was entered into Microsoft Excel and analyzed using SPSS version 18.0 (Chicago, Illinois). Categorical variables were described as proportions (\%) and continuous variables were described as medians (interquartile range). General descriptive statistics were also applied to derive means and standard deviations. 


\section{RESULTS}

A total of 200 patients were available for screening. Table 1 shows the basal characteristics of the patients in the study.

Table 1. Basal Characteristics of the 200 Patients in the Study

\begin{tabular}{|l|l|l|}
\hline \multicolumn{1}{|c|}{ Characteristic } & $\begin{array}{l}\text { Number (\%) or } \\
\text { Median (IQR) }\end{array}$ \\
\hline \hline Female sex & & $105(52.5 \%)$ \\
\hline Age (years) & $\begin{array}{l}\text { Primary or less } \\
\text { Secondary or more }\end{array}$ & $\begin{array}{l}46(18-90) \\
142(71 \%) \\
58(29 \%)\end{array}$ \\
\hline Education & $\begin{array}{l}\text { Peasant Others: business, } \\
\text { employed, housewife, retired }\end{array}$ & $\begin{array}{l}158(79 \%) \\
42(21 \%)\end{array}$ \\
\hline $\begin{array}{l}\text { Occupation } \\
\text { glucose (mmol/L) }\end{array}$ & $6.7(4.7-25.6)$ \\
\hline $\begin{array}{l}\text { Body Mass Index } \\
\text { kg/m }{ }^{2} \text { ) }\end{array}$ & & $32.4(15-45)$ \\
\hline Current smoking & & $36(18 \%)$ \\
\hline $\begin{array}{l}\text { Current alcohol } \\
\text { consumption }\end{array}$ & $38(19 \%)$ \\
\hline $\begin{array}{l}\text { Systolic blood } \\
\text { pressure (mmHg) }\end{array}$ & & $120(100-150)$ \\
\hline $\begin{array}{l}\text { Diastolic blood } \\
\text { pressure (mmHg) }\end{array}$ & $80(70-100)$ \\
\hline
\end{tabular}

32 patients $(16 \%)$ had a random blood glucose $\geq 11.1$ mmol/1 (Male: Female $=1: 1.2$ ). Out of these, 12 patients $(37.5 \%)$ never knew they were diabetic and those who knew $63 \%$ were not taking any medication. Among the diabetics, their BMI ranged from $16.9-45 \mathrm{~kg} / \mathrm{m}^{2}$ (mean $\left.=31.5 \pm 6.8\right)$. 19 patients $(59 \%)$ had a BMI $\geq 30 \mathrm{~kg} / \mathrm{m}^{2}$

The three most important risk factors were a diet high in fats $(59.4 \%)$, sedentary lifestyle $(46.8 \%)$ and family history of diabetes in a first degree relative (37.5\%) (Table 2). Among the diabetics, $5(15.6 \%)$ also had concurrent hypertension.

Dipstick urinalysis revealed glycosuria $\geq+1$ in 6 patients $(18.7 \%)$, proteinuria $\geq+1$ in 8 patients $(25 \%)$ while hematuria was present in 7 patients $(21.8 \%)$. There was no ketonuria.

\section{DISCUSSION}

The $16 \%$ diabetes prevalence is high for a rural community in Kenya where majority live on $\leq 1$ dollar/day. However, this finding is not surprising as there were high rates of obesity, physical inactivity, poor dietary habits and sedentary lifestyle in the study population. Further, according to the Kenya Diabetes Management and Information Centre, the surroundings of the region where this study was done is among the leading areas in Kenya with the highest diabetes prevalence due to poor lifestyle and dietary habits. In addition, according to the Ministry of Health of Kenya, the province where this study was done is ranked the third in terms of lack of awareness and poor knowledge on diabetes [6]. These potential factors may explain the high prevalence of diabetes in this area.

Table 2. History Obtained from the Diabetics (RBS $\geq \mathbf{1 1 . 1}$ $\mathrm{mmol} / \mathrm{l})$

\begin{tabular}{|l|c|c|}
\hline \multicolumn{1}{|c|}{ Positive History } & Frequency & Percentage (\%) \\
\hline \hline Diet high in fats & 19 & 59.4 \\
\hline $\begin{array}{l}\text { Sedentary lifestyle } \\
\text { (walking <25 minutes/day) }\end{array}$ & 15 & 46.8 \\
\hline $\begin{array}{l}\text { Family history of diabetes in first } \\
\text { degree relative }\end{array}$ & 12 & 37.5 \\
\hline $\begin{array}{l}\text { History of delivering of a baby } \geq 4.1 \\
\text { kilograms }\end{array}$ & 8 & 25.0 \\
\hline Alcohol use & 6 & 18.7 \\
\hline $\begin{array}{l}\text { Current use of estrogen-containing } \\
\text { contraceptives }\end{array}$ & 6 & 18.7 \\
\hline Tobacco use & 4 & 15.6 \\
\hline $\begin{array}{l}\text { Blurred vision and/or focal weakness } \\
\text { in the body }\end{array}$ & 5.5 \\
\hline
\end{tabular}

On examination, $43.7 \%(\mathrm{n}=14)$ had abdominal obesity while $21.9 \%(n=7)$ had various foot abnormalities (Table 3 ).

Table 3. Abnormalities on Diabetics at Physical Examination

\begin{tabular}{|l|c|c|}
\hline \multicolumn{1}{|c|}{ Abnormality } & Frequency & Percentage (\%) \\
\hline \hline Abdominal obesity & 14 & 43.7 \\
\hline $\begin{array}{l}\text { Abnormal feet (calluses/bunions/ } \\
\text { broken skin/deformities) }\end{array}$ & 7 & 21.9 \\
\hline
\end{tabular}

The current study, although not the first, has documented the highest prevalence of diabetes and its correlates in an under-privileged community. A study by Sawaya et al. [9] in one of the poorest towns in Sao Paulo, Brazil, found 30\% malnutrition prevalence in children, but obesity and overweight in adults were present in $14 \%$ and $17 \%$ respectively. In this study, malnutrition in children actually co-existed with obesity and overweight in adults. Akatsu et al. [10] (1996) documented 8\% obesity and $42 \%$ overweight prevalence among women living in a remote area in Karachi, Pakistan. Another study by Conolly et al. [11] in a deprived community in Middleborough and Cleveland U.K, found an inverse relationship between the prevalence of diabetes and socioeconomic status. It showed a significant trend between the prevalence of diabetes and quintile of deprivation score in both men and women. As the deprivation score increased, the incidence of diabetes also increased. Finally, in a study by Misra et al. [12] in an underprivileged society in New Delhi, the diabetes prevalence was $10.3 \%$ while $13 \%$ of the males and $16 \%$ of females were obese (BMI $\left.\geq 30 \mathrm{~kg} / \mathrm{m}^{2}\right)$. The above authors attributed the high prevalence of diabetes in underprivileged communities to lack of routine health checkups, poor eating habits, high level of physical inactivity and lack of awareness or poor knowledge on diabetes. These were consistent with our findings. 
Of note, the current study has revealed an increasing prevalence of diabetes in under-privileged communities in Kenya (Table 4).

Table 4. Prevalence of Diabetes in Underprivileged Kenyan Communities with Time

\begin{tabular}{|c|c|c|}
\hline Author & Year & Diabetes Prevalence \\
\hline \hline Christensen et al. $[7]$ & 2008 & $4.2 \%$ \\
\hline Mathenge et al. $[8]$ & 2010 & $6.6 \%$ \\
\hline Ayah et al. $[5]$ & 2013 & $10.5 \%$ \\
\hline Current study & $\mathbf{2 0 1 3}$ & $\mathbf{1 6 \%}$ \\
\hline
\end{tabular}

\section{The Renal Impact of Diabetes}

We believe $25 \%$ of patients in the current study could be at risk or have clinical diabetic nephropathy as evidenced by proteinuria of $\geq+1$ on urine dipstick. This figure is alarming considering majority of this population cannot even afford basic health care let alone dialysis or renal transplantation. For instance, the nearest hemodialysis unit from where this study was done is $>200$ kilometers away. This high nephropathy prevalence may have been contributed by lack of awareness and poor knowledge on diabetes and lack of frequent health checkups [6]. However, urinalysis was done on one setting and it may be difficult to differentiate intermittent versus persistent proteinuria.

The high incidence of diabetic nephropathy depicted in this study is not surprising. A study by Abdullah et al. [13] on diabetic nephropathy in Kenya found the highest ever prevalence of biopsy positive diabetic nephropathy at $46 \%$. However, recent clinical studies have documented a smaller figure. This difference may be due to different methodologies employed.

Other studies from Sub Sahara Africa and West Africa have shown high rates of diabetic nephropathy. In a crosssectional study by Mubarakali et al. [14] from Tanzania, $80 \%$ of diabetic patients had significant albuminuria while $24.7 \%$ had eGFR $\leq 60 \mathrm{ml} / \mathrm{min}$. Interestingly, none of these patients were aware of their renal disease. The prevalence of overt proteinuria $(>3 \mathrm{~g})$ in this study was $34.1 \%$. A similar study from Ethiopia found a macroalbuminuria prevalence of $20 \%$ while a study by Alebiosu et al. [15] from Nigeria found a clinical diabetic nephropathy prevalence of $28 \%$ in patients with diabetes for more than 5 years.

On the other hand, studies from America, Europe and Asia have documented smaller figures with few exceptions. Dasmahapatra et al. [16] found a $19 \%$ prevalence of overt diabetic nephropathy in African Americans in New Jersey. Both incipient and overt nephropathy correlated positively with the duration of diabetes but overt nephropathy also significantly correlated with hypertension and younger age at diabetes onset. In another study by Goldschmid et al. [17], the prevalence of microalbuminuria and nephropathy in African Americans in Atlanta was $24 \%$ and $12 \%$ respectively. Clinically significant albuminuria occurred in $36 \%$ of the patients at first presentation. Generally, African Americans have been shown to have a faster progression to end-stage renal disease and this may be due to genetic susceptibility $[18,19]$.

In a study by Lee et al. [20] from Korea, $14 \%$ of the diabetics had overt proteinuria $(>3 \mathrm{~g})$. The prevalence of proteinuria in those who had diabetes for more than 15 years was $35 \%$. In another study by Bruno et al. [21] from Italy, the prevalence of macroalbuminuria was $17.6 \%$. Both macro and micro-albuminuria significantly correlated with longer duration of diabetes and higher systolic blood pressures. Finally, De Pablos et al. [22] reported a macroalbuminuria prevalence of $11.8 \%$ from Northern Canaria Island. In this study, patients who received primary care from their family physicians had significantly lower macro and microalbuminuria prevalence than those attending the diabetic clinic without primary care.

From the above studies, the higher prevalence of macroalbuminuria and diabetic nephropathy in Sub Sahara and West Africa may be due to several factors. First, these patients are more likely to be diagnosed with diabetes at a later stage of their disease [23]. Secondly, lack of screening is a contributing factor. In some centers, screening for diabetic nephropathy is not performed at all due to limited resources $[24,25]$. Other contributing factors include inadequate treatment of complications at an early stage, poor glycemic control, lack of awareness and poor knowledge on the complications of diabetes $[23,26]$. However, caution needs to be taken when extrapolating the results of the present study due to limited sample size and lack of disease quantification.

\section{CONCLUSION}

The $16 \%$ diabetes prevalence is among the highest recorded for a community living on $\leq 1$ dollar/day. Further, evidence of renal disease as depicted by massive proteinuria warrants urgent attention in this underprivileged group. It is hoped the results will form basis for future screening of diabetic nephropathy in this part of the world where options for end stage renal disease management are limited and the incidence of diabetes continues to rise.

\section{Limitations of the Current Study}

Since this was a two-day study done during a screening event, it was not possible to do fasting blood glucose. Although fasting glucose is preferred, a random blood glucose $\geq 11.1 \mathrm{mmol} / \mathrm{L}$ has also been shown to correlate substantially with future adverse events by the Expert Committee on the Diagnosis and Classification of Diabetes. Hence a threshold of $\geq 11.1 \mathrm{mmol} / \mathrm{L}$ was used in the current study. However, to our knowledge this is the first study to describe the impact of type II diabetes in an under-privileged community in Kenya to sensitize future screening protocols in the region.

\section{CONFLICT OF INTEREST}

The authors confirm that this article content has no conflict of interest.

\section{ACKNOWLEDGEMENTS}

The authors would like to thank Mr. Doyo (Isiolo Governor), Dr. Adan Dima (Isiolo Medsup), Dr. Mohamednoor and Dr. Hassan for facilitating the screening event. 


\section{REFERENCES}

[1] 2008-2013 Action Plan for the Global Strategy for the Prevention and Control of Non-communicable Diseases. World Health Organization 2008.

[2] Deaths from NCDs. World Health Organization 2008.

[3] Boutayeb A, Boutayeb S. The burden of non-communicable diseases in developing countries. Int J Equity Health 2005; 4 (1): 2.

[4] New WHO report: deaths from non-communicable diseases on the rise, with developing world hit hardest. World Health Organization 2011.

[5] Ayah R, Joshi MD, Wanjiru R, et al. A population-based survey of prevalence of diabetes and correlates in an urban slum community in Nairobi, Kenya. BMC Public Health 2013; 13: 371.

[6] Maina W, Ndegwa M, Njenga E, Muchemi E. Knowledge, attitude, and practices related to diabetes among community members in four provinces in Kenya: a cross-sectional study. Afr J Diab Med 2011; 19 (1): 15-8.

[7] Christensen DL, Eis J, Hansen AW, et al. Obesity and regional fat distribution in Kenyan populations: impact of ethnicity and urbanization. Ann Hum Biol 2008; 35 (2): 232-49.

[8] Wanjiku M, Foster A, Kuper H. Urbanization, ethnicity and cardiovascular risk in a population in transition in Nakuru, Kenya: a population-based survey BMC Public Health 2010; 10: 569.

[9] Sawaya AL, Dallal G, Solymos G, deSousa MH, Ventura ML, Roberts. Obesity and malnutrition in a shanty town population in the city of São Paulo, Brazil. Obes Res 1995; 3(supply 2): 1075155.

[10] Akatsu H, Aslam A. Prevalence of hypertension and obesity among women over age 25 in a low income area in Karachi, Pakistan. J Pak Med Assoc 1996; 46(a): 191-3.

[11] Connolly V, Unwin N, Sherriff P, Bilous R, Kelly W. Diabetes prevalence and socioeconomic status: a population based study showing increased prevalence of type 2 diabetes mellitus in deprived Areas. J Epidemiol Commun Health 2000; 54: 173-7.

[12] Misra A, Pandey RM, Devi J, Sharma R, Vikram NK, N. Khanna. High prevalence of diabetes, obesity and dyslipidaemia in urban slum population in northern India. Inter J Obes 2001; 25: 1722-9.

[13] Abdullah M.S. Diabetic nephropathy in Kenya. East Afr Med J 1978; 55: 541-71.
[14] Mubarakali NJ, Samuel EK, Andreas M, et al. Prevalence of chronic kidney disease in diabetic adult out-patients in Tanzania. BMC Nephrology 2013; 14:183.

[15] Alebiosu C.O. Clinical diabetic nephropathy in a tropical African population. West Afr J Med 2003; 22(2): 10-5.

[16] Dasmahapatra A, Bale A, Raghuwanshi M.P, et al. Incipient and overt diabetic nephropathy in African Americans with NIDDM. Diabetes Care 1994; 17 (4): 297-304.

[17] Goldschmid MG, Domin WS, Ziemer DC, Gallina DL, Phillips LS. Diabetes in urban African-Americans. II. High prevalence of microalbuminuria and nephropathy in African-Americans with diabetes. Diabetes Care 1995; 18 (7): 955-61.

[18] Bowden DW, Colicigno CJ, Langefeld CD, et al. A genome scan for diabetic nephropathy in African Americans. Kidney Int 2004; 66 (4): 1517-26.

[19] Lipworth L, Mumma MT, Cavanaugh KL, Edwards TL, Ikizler TA (). Incidence and Predictors of End Stage Renal Disease among Low-Income Blacks and Whites. PLoS ONE 7(10) 2012: e48407.

[20] Lee KU, Park JY, Kim SW, Lee MH, Kim GS, Park SK, Park JS Prevalence and associated features of albuminuria in Koreans with NIDDM. Diabetes Care 1995; 18(6): 793-9.

[21] Bruno G, Cavallo-Perin P, Bargero G, et al. Prevalence and risk factors for micro- and macroalbuminuria in an Italian populationbased cohort of NIDDM subjects. Diabetes Care 1996; 19(1): 43-7.

[22] De Pablos PL, Martinez J, Martinez MP, Doreste JA. Prevalence of micro- and macroalbuminuria in a Canarian population of type 2 diabetic patients. Relationship with blood pressure, lipid profile, obesity and metabolic control. Diabetes Metab 1998; 24(4): $337-$ 43.

[23] Gill GV, Mbanya J-C, Ramaiya KL, Tesfaye S. A sub-Saharan African perspective of diabetes. Diabetologia 2009; 52: 8-16.

[24] Rahlenbeck SI, Gebre-Yohannes A. Prevalence and epidemiology of micro- and macroalbuminuria in Ethiopian diabetic patients. $\mathbf{J}$ Diabetes Complications 1997; 11: 343-9.

[25] Wanjohi FW, Otieno FCF, Ogola EN, Amayo EO. Nephropathy in patients with recently diagnosed type 2 diabetes mellitus in black Africans. East Afr Med J 2002; 79: 399-404.

[26] Gill G, Gebrekidan A, English P, Wile D, Tesfaye S. Diabetic complications and glycaemic control in remote North Africa. QJM 2008; 101: 793-8.

(C) El-busaidy et al.; Licensee Bentham Open.

This is an open access article licensed under the terms of the Creative Commons Attribution Non-Commercial License (http://creativecommons.org/licenses/ by-nc/3.0/) which permits unrestricted, non-commercial use, distribution and reproduction in any medium, provided the work is properly cited. 